\title{
A rare association of long QT syndrome and syndactyly: Timothy Syndrome (LQT 8)
}

\author{
U. Krause • V. Gravenhorst • T. Kriebel • \\ W. Ruschewski • T. Paul
}

Received: 9 June 2011/Accepted: 25 August 2011/Published online: 14 September 2011

(C) The Author(s) 2011. This article is published with open access at Springerlink.com

Sirs:

Classic Timothy syndrome (TS) is a rare congenital arrhythmia disorder with dysfunction in multiple organ systems, clinically characterized by long QT syndrome and syndactyly. These unique features may be accompanied by congenital cardiac defects, immune deficiency and autism [12]. The first cases of TS were described in 1992 and 1995 as sporadic cases of long QT syndrome, congenital heart disease and syndactyly [4-6]. To date, only 25 cases of classic TS have been reported in the literature [11]. Classic TS is caused by a single missense mutation G406R of exon $8 \mathrm{~A}$ of the $\mathrm{Ca}_{\mathrm{v}} 1.2$ L-type calcium channel gene (CACNA1C) and is inherited in an autosomal dominant fashion, although it usually is the result of a de novo mutation [11, 12]. This gain-of-function mutation results in an impaired open-state voltage-dependent inactivation of the L-type calcium channel, ultimately leading to a markedly prolonged myocardial action potential [12, 13]. A rare variant of TS with only two reported cases in the literature so far is caused by two different point mutations of exon 8 of the CACNA1C gene (G406R or G402S) and is clinically characterized by long QT syndrome in the absence of syndactyly [10]. As a result of prolonged QT-interval, patients with TS are prone to life-threatening ventricular arrhythmias [10-12]. Besides cardiac arrhythmias, manifestations of TS include congenital heart defects like

U. Krause $(\bowtie) \cdot$ V. Gravenhorst · T. Kriebel · T. Paul Department of Pediatric Cardiology and Intensive Care Medicine, University Hospital, Georg-August-University Göttingen, Robert-Koch-Str. 40, 37099 Göttingen, Germany e-mail: ukrause1@gwdg.de

W. Ruschewski

Department of Thoracic and Cardiovascular Surgery,

Georg-August-University, Göttingen, Germany ventricular septal defects, patent ductus arteriosus, hypertrophic cardiomyopathy and Tetralogy of Fallot [11]. Since the $\mathrm{Ca}_{\mathrm{v}} 1.2 \mathrm{~L}$-type calcium channel is widely expressed in multiple adult and fetal tissues including gastrointestinal system, brain, lungs, immune system and testis, extracardiac manifestations like facial dysmorphy, myopia, immune deficiency with recurrent infections, intermittent hypoglycemia, and hypothermia are common in patients with TS [11]. Many children with TS present with developmental delay, including language, motor, and generalized cognitive impairment [12].

We report on a now two years old female child with TS. The patient had already prenatally been diagnosed with intermittent 2:1 atrioventricular block and fetal bradycardia. On fetal echocardiography, a small muscular ventricular septal defect without other structural abnormalities was present. After 34 weeks of gestation the child was delivered by caesarean section because of premature rupture of membranes and pathological cardiotocography. Postnatal adaptation was normal with an APGAR score of 8/9 and 10 . Umbilical artery $\mathrm{pH}$ was 7.35. Physical examination revealed syndactyly of fingers 3-5 of both hands and syndactyly of toes $1-3$ of both feet. In addition the patient presented with lower set ears and bald head (Fig. 1). Initial ECG exhibited a prolonged QT-interval (QTc $600 \mathrm{~ms}), 2: 1$ atrioventricular block and a heart rate of $60 / \mathrm{min}$ (Fig. 2). Echocardiography demonstrated hypertrophic cardiomyopathy, a small muscular ventricular septal defect and a patent ductus arteriosus. Diagnosis of TS was established based on the ECG findings and the typical clinical features and was confirmed by molecular genetic analysis, which showed the typical G406R mutation of the CACNA1C gene. Because of the markedly prolonged QT-interval and the reported malignant course of TS, anti-arrhythmic treatment with mexiletine $(10 \mathrm{mg} / \mathrm{kg} / \mathrm{d}$, administered 3 times 
Fig. 1 Characteristic

phenotypic features of Timothy syndrome: bald head and lowerset ears, webbing of fingers and toes
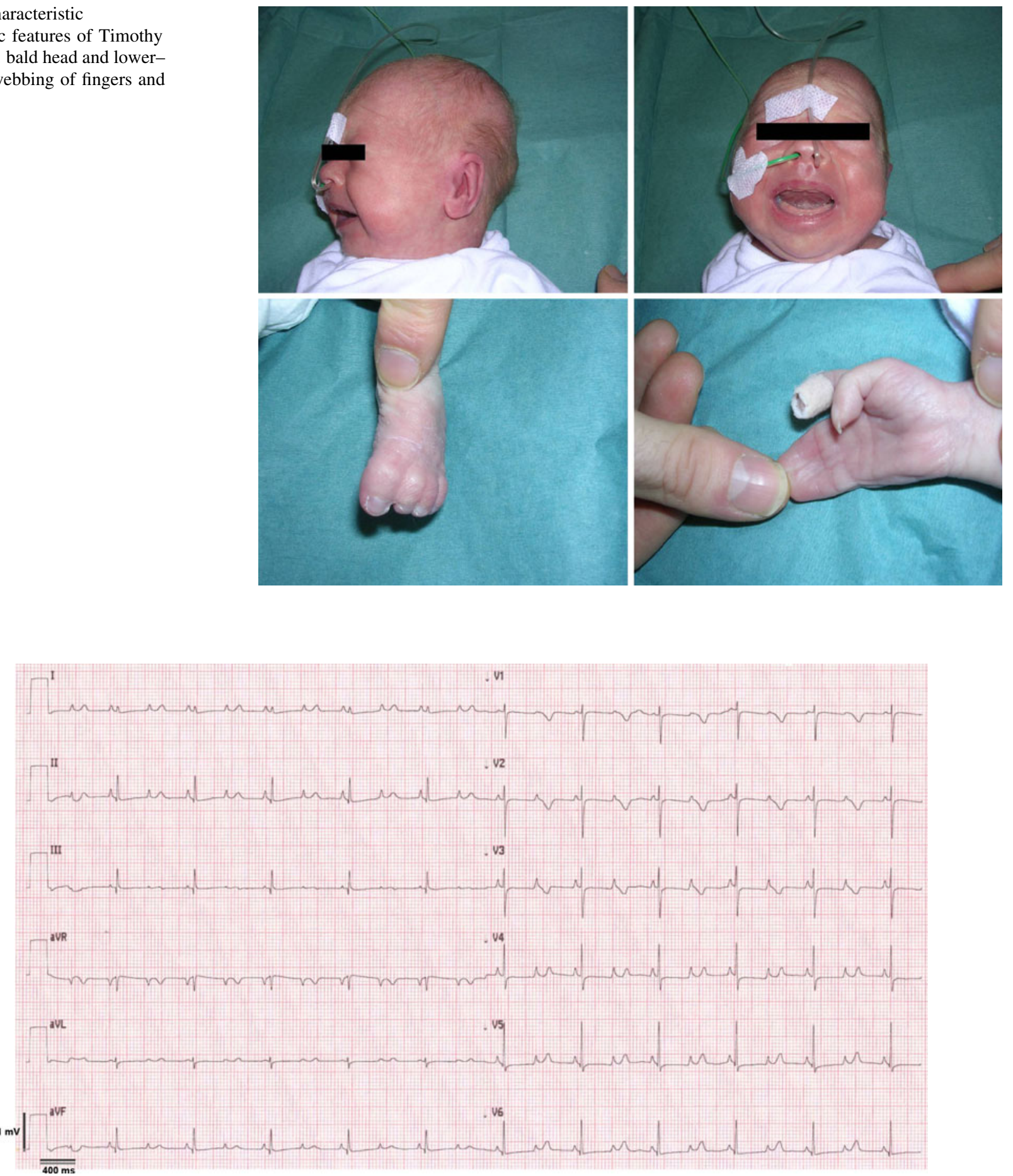

Fig. 2 ECG after birth showed a prolonged QT interval (QTc $600 \mathrm{~ms}$ ), 2:1 atrioventricular block and significant bradycardia (ventricular rate $60 / \mathrm{min})$

daily, every $8 \mathrm{~h}$ ) was started on the first day of life. Within the first 4 days of life the patient developed progressive heart failure because of persistent 2:1 atrioventricular block and a hemodynamically significant patent ductus arteriosus. Therefore, the ductus arteriosus was surgically ligated and an epicardial VVI-pacemaker (100/min) was implanted on day 4 of life. Soon after closure of the ductus arteriosus and after spontaneous restoration of normal atrioventricular conduction due to a now comparatively shorter QT-interval (QTc $560 \mathrm{~ms}$ ) after starting the patient on mexiletine, 


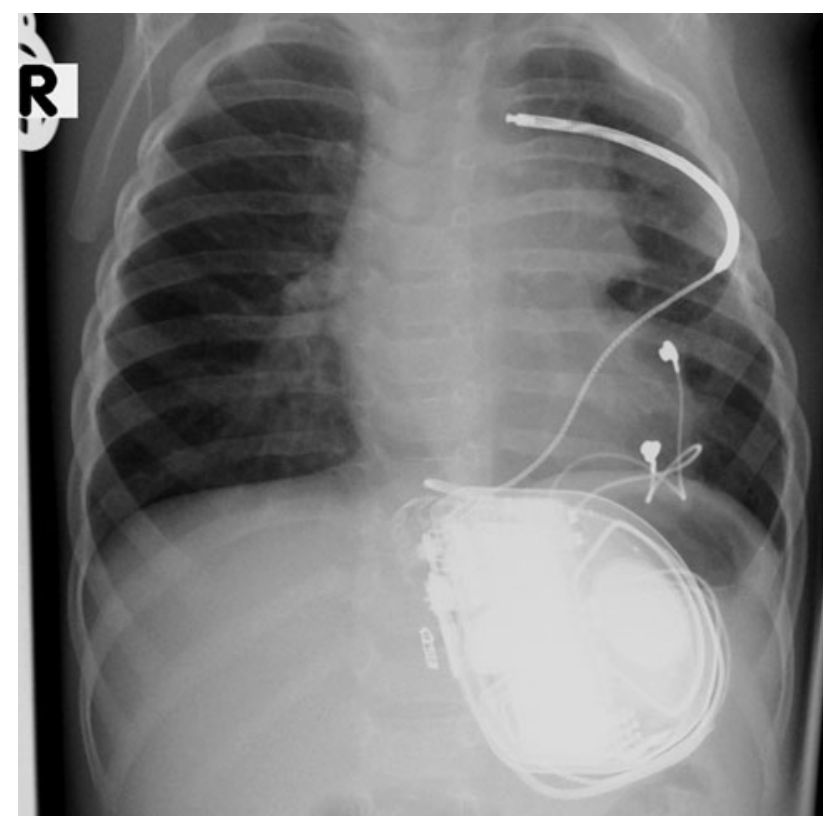

Fig. 3 Chest X-ray after implantation of an extracardiac cardioverter defibrillator system at the age of five months

cardiac function recovered. QT-interval was shortened to $560 \mathrm{~ms}$ on continued anti-arrhythmic treatment with mexiletine, the patient was in stable sinus rhythm and no ventricular arrhythmias occurred. An extracardiac internal cardioverter defibrillator (ICD) system (Medtronic Secura ${ }^{\circledR}$ VR) was implanted at the age of five months and a body weight of $4.5 \mathrm{~kg}$ (Fig. 3). The extracardiac ICD-system consists of an epicardial bipolar pace-/sense electrode (Medtronic CapSure ${ }^{\circledR}$ Epi), sutured to the epicardium of the left ventricle and a subpleural defibrillation lead (Medtronic Transvene ${ }^{\circledR}$ ), placed in the 3 rd or 4 th intercostal space. The ICD-device was placed infradiaphragmatically (Fig. 3). Intraoperative testing revealed a defibrillation threshold below $5 \mathrm{~J}$ and did not change in subsequent testings (3 months, 1 and 2 years after implantation). By the time of ICD-implantation, the VVI-pacemaker was removed. Surgery and postoperative course were uneventful and the patient was discharged home two weeks later. The patient was seen on a regular basis in our outpatient clinic with an uneventful course. At the age of 21 months, the patient developed an episode of fast polymorphic ventricular tachycardia (Fig. 4), after she had refused her medication due to upper respiratory tract infection. Ventricular tachycardia was successfully terminated by the internal cardioverter defibrillator (Fig. 4). In order to prevent future tachycardia and defibrillator discharges, propranolol $(2 \mathrm{mg} /$ $\mathrm{kg} / \mathrm{d}$, administered 3 times daily, every $8 \mathrm{~h}$ ) was added. Since then, the patient did not present with ventricular tachycardia again. No adverse side effects of either mexiletine treatment or propranolol treatment became evident to date. She shows some developmental delay regarding motor and speech development but is otherwise in good clinical condition.

The presence of long QT syndrome and the risk for lifethreatening ventricular tachyarrhythmias is the limiting factor of TS. Since ventricular tachyarrhythmia is the leading cause of death in patients with TS, effective antiarrhythmic medication and an implantable cardioverter defibrillator are the mainstay of therapy. Due to the small number of patients, no validated drug-therapy has been established so far. As in other forms of long QT syndrome anti-adrenergic $\beta$-blockers are reported to be a treatment option. Additionally calcium channel blockers and ranolazine, a novel multichannel inhibitor have been used to prevent ventricular tachyarrhythmia $[1,2,7,9,11]$. Except of one reported case, where an adult patient suffering from a rare variant of TS (TS2) was treated with a combination of verapamil and ranolazine [7], none of these drugs was proven to reliably prevent life-threatening ventricular tachycardia in patients with classic TS over a longer period of time. In our patient, we successfully used mexiletine, a class IB anti-arrhythmic drug known to shorten QT-Interval and effectively suppress the development of ventricular tachycardia in patients with long QT syndrome type 3 [8]. No ventricular tachyarrhythmias were observed until the age of 21 months, when the patient developed torsades de pointes tachycardia after having refused to take her medication. This emphasizes the highly malignant course and imperative need for a regular intake of the anti-arrhythmic medication in patients with TS. Despite an uneventful course until then, $\beta$-blocker medication was added to provide a maximum of patient safety. Since it is not uncommon in children to refuse part of their medication, a second agent with a different way of action could improve the patient's safety regarding the prevention of ventricular tachycardia. In order to control heart rate in the presence of 2:1 atrioventricular block, cardiac pacemakers are usually placed within the first days of life or early in infancy [5, 11]. Due to the malignant course of TS with a reported average age at death of 2.5 years, implantable cardioverter defibrillators are most important in preventing sudden cardiac death in individuals with TS and should be considered in every patient with confirmed diagnosis as soon as body weight allows the procedure for primary prophylaxis of sudden cardiac death even in patients without documented ventricular tachycardia [11]. In our patient an extracardiac ICD-system with a subpleural shock electrode (modified according to [3]) was placed at a body weight of $4.5 \mathrm{~kg}$ (Fig. 3).

In conclusion, patients with TS are at high risk for sudden cardiac death due to life-threatening ventricular tachyarrhythmias. Drug therapy to prevent ventricular tachyarrhythmia has not been validated due to the small 

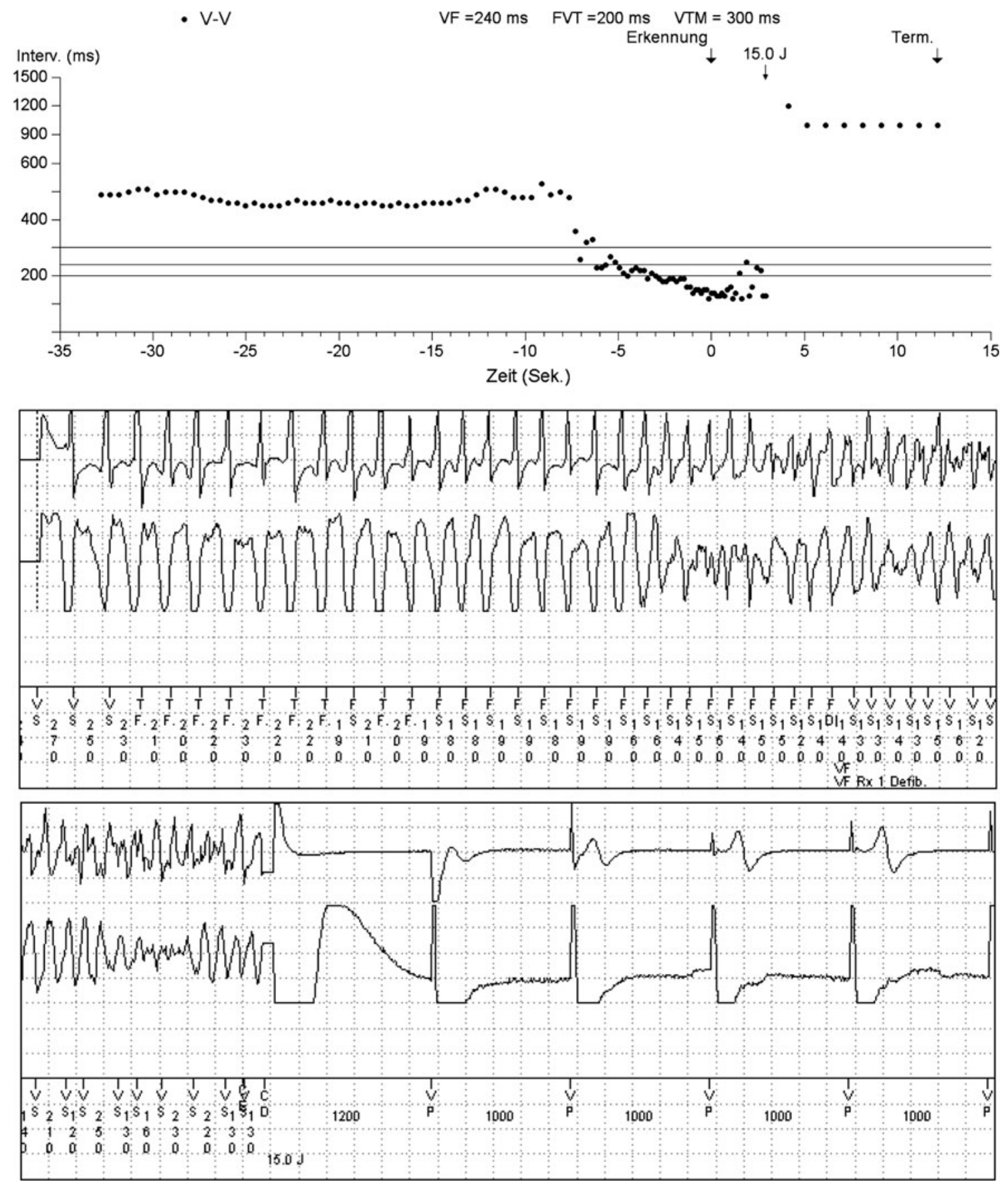

Fig. 4 At the age of 21 months, patient developed Torsade de pointes ventricular tachycardia which was successfully terminated by ICD discharge $(15 \mathrm{~J})$

number of patients but medication with mexiletine seems to be effective in patients with classic TS and should be combined with a $\beta$-blocking agent to counteract sympathetic activity. In spite of antiarrhythmic medication implantation of an internal cardioverter defibrillator is mandatory already in infancy.
Conflict of interest The authors declare that they have no conflict of interest.

Open Access This article is distributed under the terms of the Creative Commons Attribution Noncommercial License which permits any noncommercial use, distribution, and reproduction in any medium, provided the original author(s) and source are credited. 


\section{References}

1. Crotti L, Celano G, Dagradi F, Schwartz PJ (2008) Congenital long QT syndrome. Orphanet J Rare Dis 3:18

2. Jacobs A, Knight BP, McDonald KT, Burke MC (2006) Verapamil decreases ventricular tachyarrhythmias in a patient with Timothy syndrome (LQT8). Heart Rhythm 3:967-970

3. Kriebel T, Ruschewski W, Gonzalez M et al (2006) ICD Implantation in infants and small children: the extracardiac technique. Pacing Clin Electrophysiol 29:1319-1325

4. Marks ML, Trippel DL, Keating MT (1995) Long QT syndrome associated with syndactyly identified in females. Am J Cardiol 76:744-745

5. Marks ML, Whisler SL, Clericuzio C, Keating M (1995) A new form of long QT syndrome associated with syndactyly. J Am Coll Cardiol 25:59-64

6. Reichenbach H, Meister EM, Theile H (1992) The heart-hand syndrome. A new variant of disorders of heart conduction and syndactylia including osseous changes in hands and feet. Kinderarztl Prax 60:54-56

7. Shah DP, Baez-Escudero JL, Weisberg IL, Beshai JF, Burke MC (2010) Ranolazine Safely Decreases Ventricular and Atrial
Fibrillation in Timothy Syndrome (LQT8). Pacing Clin Electrophysiol 9:30

8. Shimizu W, Aiba T, Antzelevitch C (2005) Specific therapy based on the genotype and cellular mechanism in inherited cardiac arrhythmias. Long QT syndrome and Brugada syndrome. Curr Pharm Des 11:1561-1572

9. Sicouri S, Timothy KW, Zygmunt AC et al (2007) Cellular basis for the electrocardiographic and arrhythmic manifestations of Timothy syndrome: effects of ranolazine. Heart Rhythm 4:638-647

10. Splawski I, Timothy KW, Decher N et al (2005) Severe arrhythmia disorder caused by cardiac L-type calcium channel mutations. Proc Natl Acad Sci U S A 102:8089-8096

11. Splawski I, Timothy KW, Priori SG, Napolitano C, Bloise R (2009) Timothy Syndrome. In: Pagon RA, Bird TD, Dolan CR, Stephens K (eds) Gene Reviews [Internet]

12. Splawski I, Timothy KW, Sharpe LM et al (2004) $\mathrm{Ca}(\mathrm{V}) 1.2$ calcium channel dysfunction causes a multisystem disorder including arrhythmia and autism. Cell 119:19-31

13. Yarotskyy V, Gao G, Peterson BZ, Elmslie KS (2009) The Timothy syndrome mutation of cardiac CaV1.2 (L-type) channels: multiple altered gating mechanisms and pharmacological restoration of inactivation. J Physiol 587:551-565 